\title{
Method Optimization Studies on Inoculation and Isolation of the Causal Agent of Lettuce Downy Mildew (Bremia Lactucae)
}

\author{
Razieh Ebrahimzadeh ${ }^{1}$, F. Sara Dolar ${ }^{1 *}$, Kenan Sönmez ${ }^{2}$, Ş. Şebnem Ellialtıoğlu ${ }^{3}$ \\ ${ }^{1}$ Ankara University, Faculty of Agriculture, Department of Plant Protection, Ankara, Turkey. \\ ${ }^{2}$ Eskişehir Osmangazi University, Faculty of Agriculture, Department of Horticulture, Eskişehir, Turkey. \\ ${ }^{3}$ Ankara University, Faculty of Agriculture, Department of Horticulture, Ankara, Turkey.
}

*Corresponding Author: F. Sara Dolar, Department of Plant Protection, Faculty of Agriculture, Ankara University, Ankara, Turkey.

\begin{abstract}
Downy mildew disease caused by Bremia lactucae causes one of the most devastating diseases of lettuce worldwide. An obligat parasite, B.lactucae's sporulation in unnatural environments and storage is more difficult than necrotrophic pathogens and some special methods are needed to be developed. For this aim, disease samples were collected during 2016 lettuce growing seasons. The all samples were stored at -20 ${ }^{\circ} \mathrm{C}$ and $-80{ }^{\circ} \mathrm{C}$. Small leaf parts showing symptoms from the samples were dissected and spores were scraped by various methods. The spore suspensions were obtained using three methods (keep at room illumination+room temperature, room illumination+stored in ice, darkness+room temperature). In order to determine the suitable inoculation method, seedling, and detached leaf tests (blotter, floating, waxed slide test and water agar methods) were performed. A series of petri plates and seedlings were kept at $13 \pm 1{ }^{\circ} \mathrm{C}$ in the climate chamber and another series of assay were incubated at $18-21{ }^{\circ} \mathrm{C}$ until sporulation.
\end{abstract}

Among the inoculation methods used in the present study, the best results were obtained from waxed slide and MS+Agar methods. Both incubation temperatures were found to be appropriate and there was no significant difference between them.

Keywords: Lettuce, Bremia lactucae, Race, Downy mildew

\section{INTRODUCTION}

Lettuce (Lactuca sativa) belongs to the Asteraceae family and is consumed as a green salad all over the world. Turkey is among the top 10 countries that produce the most amount of lettuce [1]. According to the 2014 statistics, in 220933 areas 448513 tons of different types of lettuce is produced in Turkey [2].

Many factors that restrict the production of this product that has an important role in human nutrition exist. Among these factors, downy mildew disease caused by Bremia lactucae is one of the most important factors limiting the yield of lettuce [3]. B. lactucae attacks not only the members of the Lactuca genus, but also more than 150 species and about 40 genera of the family Asteraceae [4]. In spite of its broad host range, individual isolates of $B$. lactucae are highly host-specific and mostly limited to the same host plant species or genus [5]. This obligate pathogen is capable of infecting any lettuce growth stage from seedling to mature plant, and it sporulates mainly on the lower side of leaves. The first symptoms of downy mildew show as light green to yellow spots, bordered by the veins, on the upper leaf surface, and under optimal conditions are covered with white cottony-like fungal growth on the lower leaf surface. Eventually, affected spots will turn brown and rot away. But it is known that there may be variation in lesion types and sporulation on infected lettuce leaves [6]. Pathogen is spread quickly large areas during cool $\left(5-17^{\circ} \mathrm{C}\right)$ and wet $(\% 100)$ the growing season, and it is caused an important damage [7]. Mildew is the most important leaf disease for the lettuce in all the fields in the world that produces lettuce and infects all types of lettuce. As long as favorable conditions are present, systemic and contact-effective fungicides are recommended to control this disease which affects large areas economically however, the pathogen easily develops resistance to chemicals so the chemical struggle is not always effective and it is not economical [8-9]. For this reason, the best way to control of the disease is to use resistant lettuce varieties. A resistant variety 
breeding is a necessity in the control of the disease. A successful breeding programme for resistance against lettuce downy mildew must consider virulence distribution and racial composition of pathogen (B. lactucae) populations in a given area of interest where lettuce is grown [10]. Bremia lactucae, or downy mildew in lettuce, is genetically very variable. Even within one lettuce production field and within one isolate from a field, several races may be present. However, downy mildew has the power to develop new races rapidly, and thus break the resistance of lettuce varieties. There have been no studies on the status and races of B. lactucae in Turkey, which have so far been identified in the world as 33 (Bl: 1-Bl: 33) races [11].

For the isolation, conservation, development and inoculation on Bremia lactucae which is a biotrophic factor, the methods that work on other necrotrophic organisms are not applicable. In particular, there is a need to develop appropriate methods for storing the disease agent with long-term viability, ensuring sporulation and inoculation.

The purpose of this study is to determine B.lactucae's optimum development conditions for it to perform sporulation and to develop the inoculation method.

\section{Material AND Methods}

\subsection{Collection and Storage of the Plant Sample}

During the lettuce growing season in May and October 2016, samples were collected from Ankara province, where surveys were carried out in the fields where lettuce, curly, and iceberg types were cultivated and mildew symptoms were observed (Fig.1).

The collected leaf samples were placed in lidded and labeled plastic boxes with moistened filter paper, and brought to the laboratory as soon as possible. The samples were kept in two parallels at -20 ${ }^{\circ} \mathrm{C}$ and $-80{ }^{\circ} \mathrm{C}$.

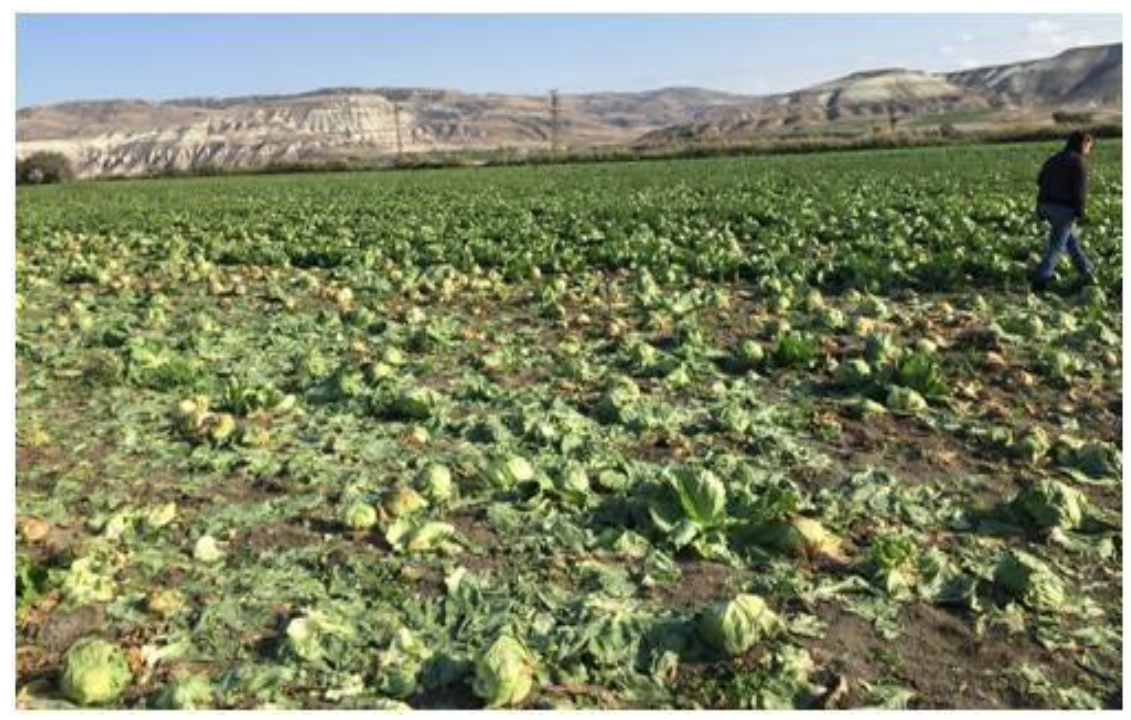

Figure1: Infected lettuce area with Bremia lactucae

\subsection{Isolation of Fungus and Preparation of Spore Suspension}

Spore suspension was obtained by gently scraping the white cottony parts of the leaf surface from the diseased lettuce leaves (Fig. 2).For the preparation of the spore suspension, sterile distilled water, non-sterile distilled water, tap water and MS-Mineral Salt (180 mg D-glucose, $1.3 \mathrm{mg}$ L-asparagine, $5.3 \mathrm{mg}\left(\mathrm{NH}_{4}\right)_{2} \mathrm{SO}_{4}, 2.4 \mathrm{mg} \mathrm{MgSO}$. $7 \mathrm{H}_{2} \mathrm{O}, 1.1 \mathrm{mg} \mathrm{CaCl}$, $3.1 \mathrm{mg} \mathrm{K} \mathrm{HPO}_{4}, 1.6 \mathrm{mg} \mathrm{K_{2 }} \mathrm{PO}_{4}$ and $1.7 \mathrm{mg}$ Thiamine $\mathrm{HCl} / 1,1$ liter distilled water) mediums were used. The sporangiophore and sporangium formation was observed from the spore suspension prepared in sterile glass petri dishes $(20 \mathrm{~cm}$ diameter) (Fig. 2). Different methods were used for spore suspension preparation.

For the first method, tubes containing the spore suspensions were kept in room temperature and illumination, for the second they were kept in ice for 2 hours in room light, while for the third they were kept in dark conditions (covered with aluminum foil to prevent light), at which the tubes were shaken in interval during 2 hour at room temperature. 


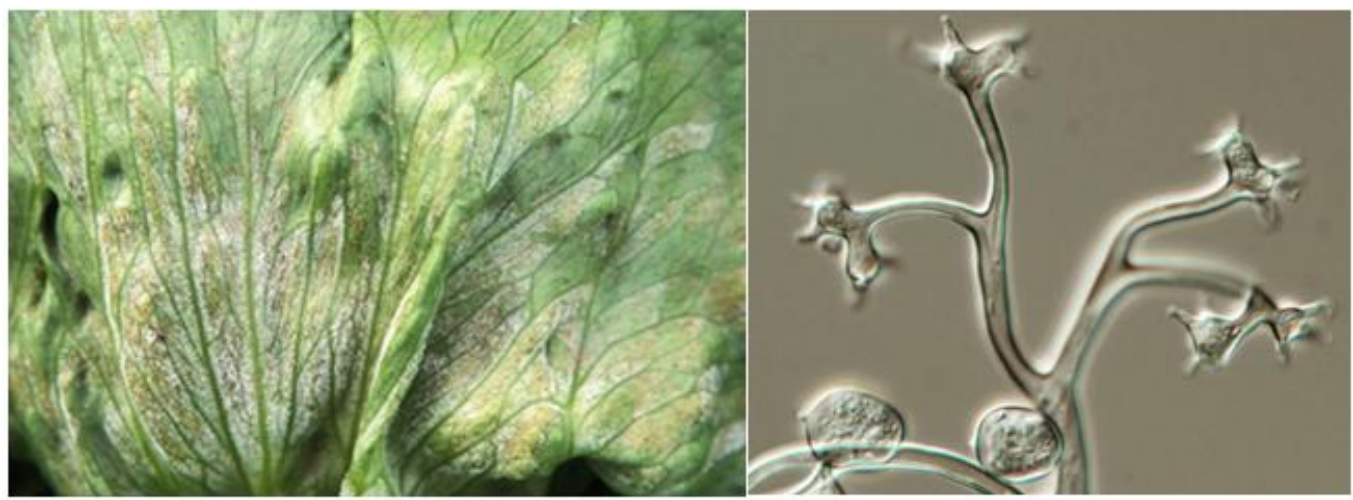

Figure2: Sporulation on lettuce leaves and sporangia-sporangiophore of Bremia lactucae

\subsection{Inoculation Methods}

Inoculation procedures were performed using susceptible lettuce varieties (Yedikule and Green Tower) in the 2-3 leaf periods. The leaves before inoculation were wiped with $70 \%$ ethyl alcohol on both sides and subsequently washed with sterile distilled water.

Seven different inoculation methods and two different incubation conditions (12 hours light and 12 hours dark conditions at $13 \pm 1{ }^{\circ} \mathrm{C}$ and $18-21^{\circ} \mathrm{C}$ temperatures) were assayed.

All the treatment was kept in dark conditions for 24 hours after inoculation. Experiments were conducted with at least 5 petri dishes and 4-5 leaf and / or leaf discs for each dish.

\subsubsection{Direct Contact}

Intensely sporulated areas were removed from lettuce leaves containing sporulation and disease symptoms, obtained from the lettuce field, and placed in contact with the underside of healthy leaves which placed on moist filter papers in sterile glass petri dishes. The petri dish was wrapped in a stretch film and allowed to incubate for 2 weeks in a growth room with 12 hours of dark and 12 hours light conditions at a temperature of $13 \pm 1^{\circ} \mathrm{C}$.

\subsubsection{Floating Method}

Spore suspensions prepared in MS media were placed into sterile glass petri dishes after which the leaves were placed so that the lower surfaces were in contact with the spore suspension. The petri dishes were covered with a stretch film (Fig. 3a). A series of petri dishes were incubated in a growth room at $13 \pm 1{ }^{\circ} \mathrm{C}$, with a $12 \mathrm{~h}$ photoperiod and an another series were incubated at $18-21{ }^{\circ} \mathrm{C}$ with a $12 \mathrm{~h}$ photoperiod.
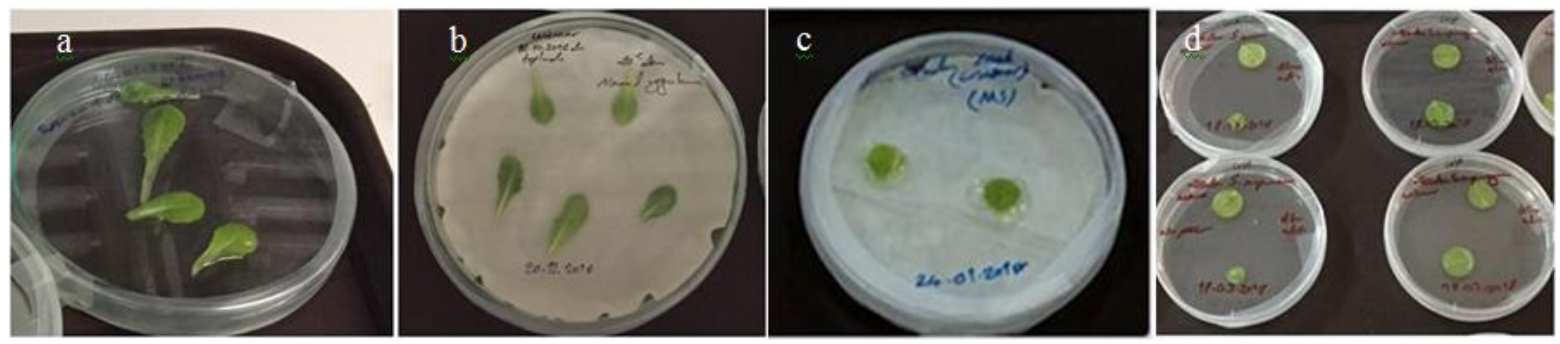

Figure3: Floating (a), blotter (b) slide (c) and water agar (d) methods

\subsubsection{Blotter Method}

In this method, moist filter papers were placed in $20 \mathrm{~cm}$ diameter sterile glass petri dishes, and the youngest leaves of the 2-3-leaf susceptible lettuce varieties were placed in petri dishes so that their upper surfaces contact the filter papers (Fig. 3b). In the blotter method, as an alternatively, instead of the whole plant leaf, $1 \mathrm{~cm}$ diameter the youngest lettuce leaves disks were placed on the filter papers. For the inoculation of the leaves, spore suspensions prepared in distilled water, MS medium, and tap water were used. All of these have been conducted as separate trials. According to the size of the leaf area to be treated using sterile Pasteur pipette, the prepared spores suspensions were placed in contact with the lower surface of 1 and / or 2 drops of leaves and the petri dishes were covered with stretch 
film. Care was taken to keep the drops (not to fall off from the surface of the leaf) on the leaves. The petri dishes were incubated for 2 weeks in the growth room at $13 \pm 1{ }^{\circ} \mathrm{C}$, with a $12 \mathrm{~h}$ photoperiod. Inoculation using a spore suspension prepared in MS medium was repeated using a parallel and placed into an incubation chamber that contains 12 light $/ 12 \mathrm{~h}$ dark periods and $18-21{ }^{\circ} \mathrm{C}$ temperature.

\subsubsection{Wax Slide Method}

In this experiment, spore suspensions prepared in MS medium of Bremia lactucae, which obtained better results in previous studies, were used. On the sterilized slides, rings of $1 \mathrm{~cm}$ in diameter were made with wax and a spore suspension of about $50 \mu \mathrm{m}$ was placed in these rings. Then leaf discs of 7 $\mathrm{mm}$ in diameter, which were cut with cork borer from the leaves of 15-day (2-3 leaf) plants, were placed so that their lower surfaces were in contact with this suspension. The slides thus prepared were placed in petri dishes containing sterile moist filter paper and incubated (Fig. 3a). A series of petri dishes were placed in an incubation chamber containing 12 hours of light 12 hours of dark period and $13 \pm 1{ }^{\circ} \mathrm{C}$ of temperature, a series of 12 hours of light 12 hours of dark period and $18-21{ }^{\circ} \mathrm{C}$ of temperature.

\subsubsection{Water Agar Method}

In this method, leaf discs ( $2 \mathrm{~cm}$ in diameter) were placed on $2 \%$ water agar so that their upper surfaces are in contact with the agar. Spore suspensions prepared in MS medium were placed on the lower surface of leaf discs with the help of a Pasteur pipette. The petri dish containing two leaf discs was wrapped with a stretch film (Fig. 3d). The petri dishes were incubated at the two different temperature conditions as mentioned above.

\subsection{6. $M S+$ Agar Method}

In this method, MS solution was added to the agar medium as a difference from the water agar method. The inoculation and incubation of the leaves is the same as the water agar method.

\subsubsection{Seedling Test}

B. lactucae spore suspension was sprayed with pressurized hand sprayer on all sides of the seedlings, especially on the underside of the leaves of the 2-3-leaf seedlings of both susceptible varieties. Following spraying, seedlings were covered with moist transparent bags and kept in the dark for the first 24 hours in growth room at $13 \pm 1^{\circ} \mathrm{C}$ and then incubated for 15-20 days in photoperiod conditions of 12 hours.

\section{RESULTS AND DISCUSSION}

An obligat parasite, Bremia lactucae's sporulation in unnatural environments and storage is more difficult than necrotrophic pathogens and even other obligat pathogens such as smut and rust and some special methods are needed to be developed. To store the disease agent, $-20{ }^{\circ} \mathrm{C}$ and $-80{ }^{\circ} \mathrm{C}$ is recommended and it is stated that spores can be kept alive for $2-3$ months in $-20^{\circ} \mathrm{C}$ but in $-80{ }^{\circ} \mathrm{C}$ this duration lengthens to 6-7 months [7].

In our study, it was observed that the spore vitality was preserved for 6 months under both storage conditions. According to the average values of all the methods applied when comparing the two temperature, storage temperatures the samples kept in $-20{ }^{\circ} \mathrm{C}$, the sporulated leaf rate was found to be $29.40 \%$ and in the samples stored at $-80{ }^{\circ} \mathrm{C}$ this rate was found to be $31.66 \%$. Both methods of storage were found to be appropriate and there was no significant difference between them (Table 1).

No results were obtained from the studies that were done with the spore suspensions prepared by using sterile distilled water. The most successful result in preparing the spore suspension was found to be at room temperature with MS solution.

Table1: Effect of inoculation methods and stored temperature on sporulated leaf ratio (\%)

\begin{tabular}{|c|c|c|c|c|c|c|}
\hline \multirow{3}{*}{$\begin{array}{l}\text { Incubation } \\
\text { temperature }\end{array}$} & \multirow{3}{*}{$\begin{array}{c}\text { Sample storage } \\
\text { temperature }\end{array}$} & \multicolumn{5}{|c|}{ Sporulated leaf ratios $(\%)$} \\
\hline & & \multicolumn{5}{|c|}{ Inoculation Methods } \\
\hline & & Waxed slide & WA & MS + Agar & Blotter & Average values \\
\hline \multirow[t]{2}{*}{$13 \pm 1^{0} \mathrm{C}$} & $-20^{\circ} \mathrm{C}$ & 22.20 & 33.33 & 33.33 & 22.72 & 27.89 \\
\hline & $-80^{\circ} \mathrm{C}$ & 40.00 & 16.66 & 66.66 & - & 41.10 \\
\hline
\end{tabular}


Method Optimization Studies on Inoculation and Isolation of the Causal Agent of Lettuce Downy Mildew (Bremia Lactucae)

\begin{tabular}{|l|c|c|c|c|c|c|}
\hline \multirow{2}{*}{$18-21^{0} \mathrm{C}$} & $\mathbf{- 2 0}^{\circ} \mathbf{C}$ & 37.50 & 16.66 & 42.85 & 26.66 & $\mathbf{3 0 . 9 1}$ \\
\cline { 2 - 7 } & $\mathbf{- 8 0}^{\circ} \mathbf{C}$ & 66.66 & 0.0 & 0.0 & - & $\mathbf{2 2 . 2 2}$ \\
\hline \multicolumn{2}{|c|}{ Average values } & $\mathbf{4 1 . 5 9}$ & $\mathbf{1 6 . 6 6}$ & $\mathbf{3 5 . 7 1}$ & $\mathbf{2 4 . 6 9}$ & \\
\hline
\end{tabular}

* This method is not applied to samples at $-80^{\circ} \mathrm{C}$.

The inoculation method was not successful in direct contact, floating and seedling test, and sporulation leaves and/or seedlings were not observed during the observation for 2 days intervals during 15-20 days of incubation. It has been reported by Lebeda and Petrzelova [7] that the most effective inoculation method is to contact of sporulated leaf blotches directly to the seedling leaf surface But in our study, this treatment method named as direct contact, did not provide any results.

When the effect of incubation conditions on the rate of sporulation in the plant is generally evaluated for all applications, this ratio is higher at $13 \pm 1{ }^{\circ} \mathrm{C}$ temperature conditions. On the contrary, in the waxed slide method, the percentage of sporulation at $18-21{ }^{\circ} \mathrm{C}$ was higher than other incubation condition (Table 1). It was found that the optimum temperature range for sporulation of the fungus is $10-15^{\circ} \mathrm{C}$ [7]. In the B. lactucae's sporulation on lettuce, temperature and humidity are very effective and the highest sporulation happened at $15^{\circ} \mathrm{C}$ and over $90 \%$ humidity [12]. Scherm and Van Bruggen [13] observed that plants incubated in 18 and $22{ }^{\circ} \mathrm{C}$ sporulation starts 5-6 days after inoculation and the plants kept in 7 and $12^{\circ} \mathrm{C}$, sporulation occurs $18^{\text {th }}$ and $11^{\text {th }}$ days, respectively.

It is known that daylight transformation to dark and light is required for the sporulation of the mildew agent. Also, colonization of the host and sporulation depends on daily internal (leaf) and external (atmospheric) water potency. In our study, the leaves were kept in a humid environment and in water, so moisture was not a limiting factor for the sporulation. Among the inoculation methods used in the present study, the best results were obtained from waxed slide and MS + Agar methods, and it was also determined that the sporulation started quickly and in a shorter time, especially with the MS + Agar method.

\section{ACKNOWLEDGEMENT}

This study was carried out by Eskişehir Osmangazi University Scientific Research Projects Office By (Project No: 1220) supported.

\section{REFERENCES}

[1] FAO. 2015. FAO (Food and Agriculture Organization), FAO Statistics Database. TUIK. 2015. website. [Online]. http://www.tuik.gov.tr/PreTablo.do?alt_id=1001\%20last\%20access\%20date:\%20March2017

[2] Yuri, J. E., Resende, G. M., Mota, J. H., Souza R. J. and Rodrigues, J. C. J. Comportamento de cultivares e linhagens de alface americanaem Santana da Vargem (MG), nas condições de inverno. Horticultura Brasileira. 22 (2) , 322-325 (2004).

[3] Crute I. R. and Davis A.A.. Specificity of Bremia lactucae from Lactuca sativa. Transactions of British Mycological Society. 1977, 69(3), 405-410.

[4] A.Lebeda, D.A.C. Pink and D. Astley. Aspects of the interactions between wild Lactuca spp. and related genera and lettuce downy mildew (Bremia lactucae). In: Spencer-Phillips P.T.N., Gisi U., Lebeda A. (eds): Advances in Downy Mildew Research. Kluwer Academic Publishers, Dordrecht, (2002).pp 85-117.

[5] I.R. Crute and G.R. Dixon. Downy Mildew diseases caused by the genus Bremia Regel. In: Spencer, D.M., The Downy Mildews. Academic Press. London, (1981) pp. 421-460.

[6] Lebeda \& I. Petrželová, Mass Screening Techniques for Selecting Crops Resistant to Diseases. Vienna, Austria, 2010, ch.15, pp 245-257.

[7] Crute I.R. and Harrison J.M. Studies on the inheritance of resistance to metalaxyl in Bremia lactucae and on the stability and fitness of field isolates, Plant Pathology. 37 (2), 231-250 (1988).

[8] Cohen, Y., Rubin, A. and Gotlieb, D. Activity of carboxylic acid amide (CAA) fungicides against Bremia lactucae. European Journal of Plant Pathology. 122 (1), 169-183 (2008).

[9] Lebeda, A. and Zinkernagel, V. Evolution and distribution of virulence in the German population of Bremia lactucae. Plant Pathology. 52 (1) 41-51 (2003).

[10] Anonymous. 2017. A new race of Bremia lactucae, Bl:33EU identified and denominated in Europe., Plantum., (IBEB-EU).,www.plantum.nl.

[11] Su, H., Van Bruggen, A. H. C., Subbaro K. V. and Schem, H. Sporulation of Bremia lactucae affected by 
tempurature, relative, and wind in controlled conditions, Phytopathology, 94 ( 4), 396-401 (2004).

[12] Scherm, H. and Van Bruggen, A. H. C. Global warming and nonlinear growth how important are changes in average temperaturee?," Phytopathology. 84 (12) 1380-1384 (1994).

Citation: R. Ebrahimzadeh, et.al, "Method Optimization Studies on Inoculation and Isolation of the Causal Agent of Lettuce Downy Mildew (Bremia Lactucae)", International Journal of Forestry and Horticulture, vol. 4, no. 2, p. 1-6, 2018. http://dx.doi.org/ 10.20431/2454-9487.0402001

Copyright: (C) 2018 Authors. This is an open-access article distributed under the terms of the Creative Commons Attribution License, which permits unrestricted use, distribution, and reproduction in any medium, provided the original author and source are credited. 